\title{
COSO in the Worldbank
}

\author{
Fayezul H.Choudhury and Philip Mitchell \\ The Worldbank \\ 1818 H Street, N.W. \\ Washington D.C. 20433, USA
}

Key words: $\quad$ COSO, internal control, control model, control framework, control self assessment, risk assessment, corporate governance

\begin{abstract}
:
This paper describes the importance of internal controls to the Worldbank and the project that was initiated to implement the COSO internal control framework in the Worldbank. The paper concludes with benefits of the project and some challenges for the future activities.
\end{abstract}

\section{INTRODUCTION}

I am pleased to be with you all today, and I am glad to have the opportunity to contribute to the dialog on a subject that is receiving increasing attention, in both national and international circles, i.e. the evolution and relevance of internal control models.

In the past internal control was primarily the purview of the auditors, where the emphasis was on retrospectively identifying control weaknesses. This is evolving to where I believe internal control will be in the future, and that is a fully integrated part of an entities key processes, behaviors, and culture. I believe that when we achieve this goal we will be making a very significant contribution to the efficiency and effectiveness of the World Bank.

We are not at this point yet at the World Bank, although we have made significant progress towards this goal. What I would like to do in my time with you is to review the experiences we have had at the World Bank in implementing an internal control model, i.e. COSO ${ }^{1}$.

${ }^{1}$ COSO is the acronym for the Committee of Sponsoring Organizations of the Treadway Commission which published the "Internal Control -Integrated Framework". 1994. 
I will tell you a little about the World Bank, who we are; why we felt the need to broadened our approach to internal control; why we felt it was necessary to introduce a "modern control framework" such as COSO; and I will also briefly describe our implementation process.

I will conclude by describing both the current status of COSO in the World Bank, and what I see as the benefits COSO has provided. I hope at the conclusion of my presentation to be able to take any questions you may have. But firstly let me provide you with some relevant background on who we are.

\section{WHO ARE WE?}

The World Bank is an international development institution whose goal is to reduce poverty by promoting sustainable economic growth in its client countries. The World Bank was originally created after the second world war to participate in the reconstruction of Europe. We have evolved both in terms of our role, and in terms of the scale of our efforts. During FY99 we lent approximately $\$ 29$ billion to our client countries.

The World Bank consists of five closely associated institutions: the International Bank of Reconstruction and Development (IBRD), the International Finance Corporation (IFC), the International Development Association (IDA), the MultiLateral Investment Guarantee Agency (MIGA), and the International Center for Settlement of Investment Disputes (ICSID). These five institutions constitute the World Bank Group. We provide loans and credits, policy advice based on economic and sector analytical work, technical assistance, and increasingly, knowledgesharing services to our client countries.

The World Bank is owned by more than 180 member countries whose interests are represented by a Board of Executive Directors, and a Board of Governors.

We raise money for development programs by tapping the world's capital markets, and, in the case of the IDA, through contributions from wealthier member governments.

IBRD, is one of the world's most prudent and conservatively managed financial institutions, the IBRD issues AAA-rated bonds and other debt securities to pension funds, insurance companies, corporations, and other banks around the globe. IBRD charges interest to its borrowers at rates which reflect its cost of borrowing. Loans must be repaid in 15 to 20 years; there is a three to five-year grace period before repayment of principal begins.

The International Development Association was established in 1960 to provide concessional assistance to countries that are too poor to borrow at commercial rates. IDA uses interest-free loans (which are known as IDA "credits"), technical assistance, and policy advice. IDA credits account for about one-fourth of all Bank 
lending. Borrowers pay a fee of less than 1 percent of the loan to cover administrative costs. Repayment is required in 35 or 40 years with a 10-year grace period.

Nearly 40 countries contribute to IDA's funding, which is replenished every three years. Donor nations include not only industrial member countries such as France, Germany, Japan, the United Kingdom, and the United States, but also developing countries such as Argentina, Botswana, Brazil, Hungary, Korea, Russia, and Turkey, some of which were once IDA-borrowers themselves.

\section{WHY ARE CONTROLS IMPORTANT TO US?}

As with any organization we strive to use our resources responsibly. This includes ensuring financial integrity, for example, we must ensure that our financial statements are reliable and accurate. This is not only the "right thing to do" it is also an important part of maintaining our triple-A rating.

It is also our responsibility to provide "reasonable assurance", to both management and the Board, on the adequacy of its internal control systems. We have a resident full time Board whose function includes "content overview" and close supervision of activities.

We feel that in order to enhance controls we must build control awareness in the units doing the work as well as individual accountability for controls throughout the organization. This is a cost effective approach, and it is also sensible as people in the business units know both the function and the control issues surrounding the function.

Controls are also important to us as the World Bank is always operating in a tight budget environment and it has become increasingly appropriate that we not only ensure that funds are used for the purposes for which they are intended, but that they are also used "efficiently and effectively". As the demand and competition for budgets increases so does the need to introduce more effective control.

Thus when we look at why controls are important to us we see several key elements, i.e.:

- our fiduciary responsibility,

- our goal of reassuring the Board and management on the adequacy of our internal controls,

- our response to budget pressures leading us to include controls related to efficiency and effectiveness in our scope,

- and our realization that, for controls to be effective, all individuals within the World Bank need to be held accountable for both the processes they perform, and the controls related to these processes. 
With these factors as background COSO seemed relevant and a natural fit. However, before I launch into our implementation of COSO I want to take a few minutes to describe the main features of the World Bank's control framework before COSO was adopted.

\section{WHAT WERE THE MAIN FEATURES OF THE CONTROL FRAMEWORK BEFORE COSO?}

It is important to point out that the control framework that we used before COSO was adequate for meeting its primary purpose, i.e. ensuring its financial statements were reliable and that funds are used for the purposes for which they were intended. The Bank has always had some level of activity to ensure this was the case.

The Bank followed industry standards as they existed at the time and has relied on internal and external auditors, plus standard controls such as:

- Proper Approval

- Segregation of Duties

- Expert staff

- Solid systems controls

- Control reports

- Periodic Review

However, we had no over arching control framework or ideology. Separate control units existed but they were not unified by a coherent institutional strategy on controls.

\section{WHY COSO?}

So why did the World Bank implement COSO if we were doing such a good job? We needed a more comprehensive control model that included not only a review of controls surrounding the financial statements but also:

- included a review of controls surrounding efficiency and effectiveness of operations, and also

- included compliance with applicable laws and regulations within its scope. I should point out that on this last point our focus was not so much compliance with national laws and regulations but, as we are an international organization, we focused more on compliance with regulations within the World Bank.

COSO also included broader control issues such as corporate governance and this was appealing to us as within the Bank itself we had changes in management with the appointment of a new Controller, and subsequently a new President. These 
elements, plus a strong emphasis on budget cutting, the introduction of a "Strategic Compact" that emphasized behavioral change and individual accountability, and a major systems re-engineering, made the implementation of COSO a "natural event". Or so we thought at the time.

As COSO was the first of the "modern control frameworks" to be published, and it met the Bank's need for a more comprehensive approach to controls, it was adopted by the Controller and approved by the Audit Committee.

The fact that COSO was the first control framework that was mandatory for financial institutions within a country (USA) provided a certain legitimacy to the model, and made the model easier to "sell".

I should point out that although the World Bank's control framework still goes under the COSO name, largely because we have established "name recognition", we have reviewed subsequent control frameworks as they emerged. These are often based on COSO and still bear a strong resemblance to COSO. Where appropriate we incorporate relevant advances. For example the Basle Committee report: "Enhancing Corporate Governance for Banking Organizations", September 1999, was the first model that had such a strong international focus on the Banking sector and we are reviewing this model to assimilate its strong points.

A review of the control elements in the COSO control framework helps emphasize why it was applicable to the Bank ${ }^{2}$.

1. Control environment: (Soft or human behavior type issues): ethics, management style, tone at the top and how it influences behaviors surrounding controls. These were not adequately addressed in the traditional approach to control.

2. Risk: in terms of not achieving objectives: includes risks at the business unit level and risk at the corporate level. Formerly risk assessment in the operational parts of the Bank:

- did not include risk in terms of the sustainability of the organization;

- did not emphasize raising business unit awareness of risks;

- did not emphasize balancing risk and opportunity;

- did not look at reputational.

3. Control Activities: includes the more traditional controls:

- $\quad$ are the policies and procedures that help ensure management directives are carried out;

- reviews of actual performance versus budgets;

- information processing includes checks of the accuracy, completeness and authorization of transactions, and controls surrounding access;

\footnotetext{
${ }^{2}$ The elements of the COSO model have been extracted from: "Internal Control - Integrated Framework". July 1994. Committee of Sponsoring Organizations of the Treadway Commission.
} 
- data entered are subject to edit checks or matching to approved control files, file totals are compared and reconciled to prior balances and control accounts.

As you can see the traditional control methods have not been neglected in COSO as they are included here under control activities.

4. Information and Communication: Pertinent information must be identified, captured and communicated in a form and timeframe that enables people to carry out their responsibilities and meet their business objectives. Focus includes human communication and deals with:

- internally and externally generated information and events;

- activities and conditions necessary to informed business decision making and external reporting;

- $\quad$ systems support for strategic initiatives;

- integration with operations;

- how effective is communication in terms of bad news flowing up and down the organization, and between peers.

Information is needed at all levels of an organization to run the business, and move towards achievement of the entity's objectives in all categories operations, financial reporting, and compliance. In the traditional approach there was a more micro level focus on information.

5. Control Monitoring: COSO included a review of the internal control systems a process that assesses the quality of the system's performance over time. Helping ensure that systemic control weaknesses are more readily identified.

\section{APPROACH USED IN ROLLING OUT COSO}

In rolling out COSO our tangible objective was to: ensure that management felt comfortable in signing an assertion on the adequacy of controls surrounding the financial statements, and that the external auditors can attest that they concur.

In order to arrive at the point where we have a reasonable assurance as to the adequacy of the controls we:

- have managers throughout the Bank sign a Letter of Representation in which they assert on the adequacy of controls and identify any control weaknesses that are material, and

- utilize a Control Self Assessment (CSA) approach that builds awareness and individual accountability, focuses on business unit objectives, risks and mitigating controls.

The Control Self Assessment approach was implemented using the following principals/approach:

- individuals closest to the work know it best and are in the best position to identify control weaknesses and strengths; 
- implemented by business units themselves;

- controls group provide intellectual leadership, counsel and advice;

- active involvement of Internal Audit Department and external auditors;

- business units take over the process at the end of 1st year, assisted by "COSO Champions".

These principles fit nicely with our objectives of building control awareness and increasing individual accountability and responsibility throughout the World Bank.

In implementing Control Self Assessment we used the following methods:

- Control Self Assessment workshops. This consisted of a "Top-down" selfassessment session with the managers of a Vice Presidential group;

- a series "Bottom-up self-assessment workshops", aimed at carrying our bottom up workshops with at least $20 \%$ of the units in each Vice Presidential group;

- a critical review of business objectives, key risks and controls, and we also

- required business units to prepare Action Plans to address control issues.

Each Control Self Assessment workshop consists of ${ }^{3}$ :

- An Introduction: Designed to educate the audience on control and how it is a critical part of their business.

- A Situation analysis: Which captures from the participants:

- The business objectives, as they are understood as opposed to how they are written; and

- The main strengths that the participants identify as assisting in meeting the business unit objectives, and the weaknesses that the participants perceive impede meeting the business unit objectives.

- An Assessment of key control indicators. Using electronic voting technology the participants vote anonymously rating control risks associated with their business objectives. Results are displayed and discussed and control issues are identified and solutions documented.

- An Action Plan is developed and then control weaknesses are followed up on and assessed in terms of residual risk at a later date

As part of the businesses unit risk and controls we require that business units prepare documentation on the following:

- the business unit objectives;

- risks and mitigating controls;

- key transactions and controls, and also emphasized that business units', and

- results of testing of controls related to key processes and transactions.

${ }^{3}$ The methodology we used in our Control Self Assessment Workshops was developed by PDK Control Consulting International Ltd. For a more complete description of this approach see: Control Self-Assessment Workshop Facilitator's Guide. The World Bank. CSA Library Series 97-1. Published by the Institute of Internal Auditors. 


\section{INITIAL ROLL OUT OF COSO}

COSO CSA was first piloted in the Finance Complex as this allowed us to refine our tools and also examine financial risks that have major impact on the financial statements of the Bank. The emphasis on the reliability and completeness of the financial statements still remains a primary objective of our control philosophy.

Once we had rolled COSO out in the Finance Complex we then introduced COSO to the "operational areas" of the Bank where we included more emphasis on efficiency and effectiveness of operations. We have now completed around 150 workshops covering most parts of the Bank.

\section{CURRENT STATUS}

We have made significant progress in raising control awareness and accountability for controls throughout the Bank. This is often evident in any conversation related to the use of budgets.

We have also made some progress in building internal capacity in the business units outside the financial complex. We still have to make more progress in the aspect of our COSO work and we are currently drafting a "COSO Implementation and Maintenance Manual", and a "Administrative Budget Controls Manual" to provide fundamental tools to business units.

Indicators that we have gained acceptance for both COSO, and some of the controls issues we have raised include:

- the Audit Committee is focusing on corporate risk and control and their role;

- our COSO Report (which provides commentary on the adequacy of controls) to the Board, was well received and they are looking for ways to respond control issues we have identified;

- we have established an effective voice and dialog on control issues; and

- we have developed effective links with operational units that have quality and efficiency and effectiveness as part of their mandate.

In terms of going forward with our COSO implementation in the near term we need:

- to consolidate progress and have business units carry out more rigorous control activities down to the transaction level; and

- to address control issues associated with the introduction of new enterprise wide systems. We have introduced SAP to replace the more than 40 legacy administrative transaction systems. This has been a major investment in both monetary and human resources and is imposing a new way of doing business. It has also brought with it a different set of controls that require understanding and acceptance. 
Although the World Bank is in the standard "productivity dip" associated with absorbing the changes that SAP brings, it is my view that by rolling out COSO we have established a control mind-set that reduces the control issues that such a massive change normally entails. Specifically, by having people at all levels of the Bank considering control as part of their responsibility we have reduced the risk.

In terms of my overall objective of having controls integrated into the business processes of the Bank from planning to ex poste review, we still face an attitude of "well if its institutionally required we will fit it in". This is not the case everywhere in the Bank but it is my view that it is still the prevailing attitude. We will keep working on this.

\section{FUTURE STATUS}

Although we have had some successes with our COSO roll-out we still face significant challenges. These include that we need to:

- ensure controllers transitions to a "coordination and quality control role", and concentrate on identifying the over arching control issues in the Bank. This can only be accomplished as the business units throughout the Bank take over COSO activities such as CSA workshops and compliance reviews.

- back-fill the controls awareness gains we have made with a strong emphasis on traditional controls. This is particularly important with the introduction of a corporate wide system (SAP);

- implement a corporate risk model and link risk to control;

- maintain the progress and direction we have made in the face of the fact that we will be getting a new controller;

- deal with the continual erosion of resources throughout the Bank with the increased risk that controls will be eroded to make up for budget short falls.

\section{CHALLENGES AND BENEFITS}

Looking back on the challenges we have faced I would say that initially the issue was acceptance. There was an aversion to the word "control" in those areas of the Bank that were not primarily financial in focus, you could almost hear:

- "controls, we have enough safeguards already, don't impose more obstacles";

- "Why is the Controller getting into areas of efficiency and effectiveness";

- "We don't have time for this".

We also faced a significant skills development issue. Staff tasked with rolling out COSO had either an accounting or finance background and they were not necessarily prepared, or able, to deal with the "softer" human and behavioral issues associated with an internal control model such as COSO. This was especially true 
when it comes to facilitating a Control Self Assessment workshop. We were able to identify enough of our staff who could meet the new requirements, and we supplemented them by using a qualified external consulting company.

Initially we had to develop tools that were effective in identifying control issues and that had credibility with our clients. We had to reach a point where the control processes we use was seen to add value to our clients' business.

We have largely overcome these challenges and we are now dealing with the following issues:

- Residual reluctance to accept COSO, sometimes still viewed as an "Institutional Requirement", or an "Un-funded mandate".

- Ensuring that Bank wide control issues receive proper attention and are resolved. This challenge exists at the business unit level and at the institutional level. This is not an issue for controls related to the financial statements but it does exist in areas such as corporate governance, and efficiency and effectiveness of operations.

In terms of the benefits COSO has provided I would say it has been effective in:

- raising control awareness;

- obtaining greater accountability down to the staff member level in the Bank;

- providing some gains in terms of improving team work;

- making soft issues (which are often the key control issues) part of a control review;

- gaining management's, and the Board's, attention on over arching control issues;

- reducing "control aversion" by bringing a more appealing image to control;

- keeping the Bank up with the industry in terms of controls, and

- helping the controller play a more proactive and corporate wide role in the Bank.

At this point I would like to conclude my formal remarks and I would be glad to answer any questions or respond to any observations any of you may have. 